\title{
A ESPACIALIDADE RELIGIOSA DA IGREJA MADALENA SOFIA BARAT E SANTO EXPEDITO SOB A ÓTICA DA METODOLOGIA GOFFMANIANA
}

\author{
Religious Spatiality Magdalene Church Sofia Barat and Holy Expedito under the perspective of \\ methodology goffmann
}

\author{
Ana Helena Corrêa de Freitas Gil \\ Doutora em Geografia \\ Professora de Geografia do Instituto Federal do Paraná \\ anahgil@gmail.com
}

\begin{abstract}
RESUMO: O presente artigo tem por objetivo apresentar a espacialidade religiosa da Igreja Madalena Sofia Barat e Santo Expedito. Tendo como base as leituras do cotidiano, realizadas sob a ótica da metodologia de Erving Goffman. Desse modo, são analisadas as situações sociais que se formam através de um acervo simbólico, em palcos de atuação. Dessa maneira, cada pessoa desempenha um papel ao interagir com os outros através de comportamentos físicos e verbais, criando também um papel de desejo, que utiliza a aparência para convencer o outro de sua intenção mascarada por sua própria atuação. Assim, a vida do teatro e vida cotidiana apresentam inúmeros paralelos, principalmente quando estabelecem palcos. Esse palco de interações permite que, de acordo com Berger e Luckmann (1999, p.38), "a realidade da vida cotidiana apareça já objetivada, isto é, constituída por uma ordem de objetos que foram designados como objetos, antes da minha entrada em cena." $\mathrm{O}$ indivíduo que se apresenta como personagem será considerado o que é, um ator desempenhando seu papel em um palco pré-estabelecido. A abordagem teatral na vida social é o centro da argumentação de Erving Goffman. Nesse contexto, Goffman diferencia entre um desejo individual-pessoal e um conjunto interativo coletivo. Assim, se permite a suposição de dois espaços; de um lado um espaço da personalidade autêntica e, de outro um espaço social de interação. A teatralização da vida cotidiana se estabelece entre ambos e, consequentemente cada ação que um indivíduo executa solicita que os observadores dessa ação levem a sério, quer dizer, que julguem como autêntico, a impressão do que está sendo apresentado. Inserida na dimensão traçada, estão categorias como as Instituições formadoras do Bairro Alto em Curitiba- PR, temos a dimensão religiosa da Igreja Madalena Sofia Barat e Santo Expedito, um dos palcos com uma história extremamente antiga, portanto bastante ritualizada, com claros papéis entre lideranças religiosas e os fiéis, além dos outsiders das cerimonias.
\end{abstract}

Palavras-chave: Espacialidade religiosa; Cotidiano; Metodologia goffmaniana.

ABSTRACT: This article aims to present the spatiality of religious church Madeleine Sophie Barat and St. Expedite. Based on the daily readings, conducted from the perspective of Erving Goffman methodology. Thus, analyzing social situations that are formed through symbolic acquis stages of operation. Thus, each person plays a role interacting with others through physical and verbal behaviors, also creating a role of desire, which uses appearance to convince the other of their own performance by intention. Thus, the life of the theater and everyday life have many parallels, especially when set stages. This stage allows interactions, according to Berger and Luckmann (1999, p.38), "the reality of everyday life appears already objectified, that is, consisting of an array of objects that were designated as objects before my entry on the scene "an individual who appears as a character will be considered what it is, an actor playing a role in a pre-set stage. The theatrical approach in social life is the center of the argument of Erving Goffman. In this context, Goffman differentiates between an individual-personal desire and collective interactive set. Thus, if the assumption allows two spaces; on one side a space of authentic personality and on the other a social interaction space. The theatricality of everyday life is established between them and consequently every action that an individual performs requests that observers take seriously this action (ie judge how authentic) the impression of what is being presented. Inserted into the dimension that we draw as training institutions in the Bairro Alto - Curitiba- PR , we have the religious dimension of Madeleine Sophie Barat Church and St. Expedite, one of the stage with a very ancient history, so quite ritualized, with clear roles between religious leaders and faithful, beyond the outsides of ceremonies.

Keywords: Religious spatiality; Everyday life; Goffman's methodology. 


\section{Introdução}

O presente artigo busca apresentar a espacialidade religiosa da igreja Madalena Sofia Barat e Santo Expedito sob a ótica da metodologia Goffmaniana. Procuraremos fazer uma leitura do cotidiano e, como essas relações se constituem, bem como são representados os papéis sociais dentro dessa igreja.

Para tal, tivemos a oportunidade de entrevistar o padre responsável e, também de participar de missas proferidas por ele. Não entramos em contato direto com as pessoas que frequentam essa espacialidade, apenas nos retivemos a observá-las.

O encantamento de estar participando de uma comunidade religiosa fica estampada em alguns rostos dos fiéis. Há desse modo, um envolvimento espontâneo de escutar as palavras do padre e tentar absorvê-las, claro que a importância desses encontros varia de pessoa para pessoa, com seu discurso baseado na Bíblia, o padre vai aos poucos repassando a sua mensagem. Todavia, alguns participam da missa como um sinal de obrigação, nasceram dentro da religião católica e seguem os passos de seus antepassados, assistem a missa, marcam presença, o que não significa que durante há sua semana ou de sua vida irão adotar os ensinamentos. No entanto, como frisa Goffman (2011, p.110), um foco principal de atenção à conversa é algo único, pois ela cria para o participante um mundo e uma realidade que tem outros participando dela. Gestos, atitudes, palavras, a forma de demonstrar "sua fé" fazem parte desse ritual que é oferecido aos crentes, escolher o que seguir, depende de cada um.

Dessa forma as indicativas de Goffman nos levam a crer que todos os indivíduos interagem influenciando e sendo influenciado em seu cotidiano como em um palco de teatro, representando seu papel frente a amigos e familiares. Os crentes se encontram na igreja e, podem adotar uma postura sincera ou cínica. Ao chegar à presença de outro, o indivíduo desempenha um papel e, solicita que esses levem a sério o papel que está representando, levando a sério a impressão sustentada perante eles, o que podemos observar com a entrada do padre para celebrar sua missa na igreja Madalena Sofia Barat e Santo Expedido.

Para melhor compreensão, apresentaremos uma breve revisão teórica a partir do qual faremos um movimento interpretativo sobre o quadro cotidiano dessa instituição. 


\section{A metodologia Goffmaniana}

Erving Goffman (1922-1982) foi um sociólogo canadense que desenvolveu sua teoria baseado na observação das pessoas em seus ambientes, ou seja, como cada pessoa representa seu papel no dia-a-dia e, como cada um concebe seu papel e pretende mantêlo na presença de outros.

A metodologia de Goffman começou a ser pensada após ele assistir uma peça de teatro onde começou a refletir que em um palco as pessoas se caracterizam e representam papéis e, que na vida cotidiana existem vários palcos onde as pessoas assumem papéis já pré-concebidos e representam como em uma peça de teatro.

A percepção de Goffman, denominada interacionista da sociedade não só analisa as interações sociais destacando sujeitos, na grande maioria indivíduos, mas faz também uso da metáfora teatral por considerar pessoas como atores que se apresentam com suas atuações num teatro que podemos chamar "realidade". Goffman chega nessa proposição pela observação que a integração do mundo social acontece geralmente não tanto por individualidades autônomas, mas pela apropriação de papéis por cada indivíduo. Mesmo assim, sua visão não se restringe aos papéis com funções fixas, pelo contrário, permite sempre portas abertas para o desenvolvimento de novos papéis e novas representações pelos indivíduos.

As relações entre os atores se dão pelos ritos organizados em interações cotidianas através da formação de papéis. O Eu social, que Goffman denomina self, cria um território de papéis, um espaço pessoal, que cada um constrói,cercando sua atuação. Assim, sentar-se ao lado de outra pessoa em um banco de uma praça, ou no banco da igreja, pode ser vivenciado pelo outro como uma intromissão ao espaço dele, criando um confronto de papéis com um resultado espacial. Evidencia-se, neste caso, que a junção de tais espaços "encenados" na realidade vivida necessita de negociações entre estes atores. Estas podem acontecer através da obediência ou desobediência de regras ou tradições, sempre em comunicações imediatas. Quando pessoas entram na presença de outras, elas assumem papéis e são participantes do que O que Goffman (2010, p.28) acaba denominando de ocasião social, que ocorre em um determinado local e tempo, facilitados por equipamentos fixos, o que de certa forma possibilita um padrão de conduta como apropriado para o local, como o de uma instituição religiosa. O ambiente possui cômodos definidos, hall de entrada, secretaria, sala de direção, sala dos 
professores, salas de aulas, entre outros, que já estão preparados para receber os alunos e possuem uma programação de atividades, bem como regras e normas que devem ser seguidas. No caso da instituição religiosa, a utilização de uma vestimenta própria pelo padre, do silêncio quando ele entra na igreja para fazer a celebração da missa, e o levantar das pessoas com sua entrada, demonstram um sinal de reverencia e respeito ao que está sendo apresentado, ele é uma pessoa como tantas outras, mas ao chegar ao altar com vestimentas próprias para celebração, ele passa a ser uma autoridade, um representante da religião preparado para executar seu papel.

Como ressalta Goffman (2010, p.40) se o indivíduo quiser estar na situação totalmente capacitado e socialmente aceito, será necessário um certo nível de prontidão de suas ações e forma de agir. Um padre se prepara durante anos para exercer o seu papel, dedicando horas e praticamente sua vida a igreja, o que veremos mais detalhadamente ao longo do texto.

A ideia da interação social influencia muito, até hoje, as mais diversas ciências sociais. Podemos considerar Goffman como um ícone nesses estudos.

Goffman faleceu em 1982, deixando um legado teórico e metodológico de inestimável importância, que foi utilizado, entre outros, na psicologia social, na psiquiatria, na sociologia, na linguística aplicada, no direito e atualmente também na geografia.

Como a compreensão da sociedade no interacionismo simbólico tem sua base em ações, o método adotado por Goffman sempre é monográfico e empírico, ou seja, trata-se de estudos de casos em profundidade sempre de pequenos grupos. Nestes grupos, o olhar se foca em observações e interpretações de representações das pessoas.

Necessita-se, como uma das principais características, a imersão do pesquisador nestas pesquisas. Neste contexto, a perspectiva interpretativa é fundamental durante a condução da pesquisa, porque deixa clara a subjetividade do pesquisador no evento da pesquisa (Kaplan \& Duchon, 1988).

Trata-se, assim, de uma pesquisa qualitativa, na qual o pesquisador é um interpretador participante da realidade (Bradley, 1993), se apropriando do fenômeno social como um diretor (que dirige a pesquisa) junto com seus atores, assim, reproduzindo de certa forma uma peça de teatro. Consequentemente, se desenvolve a compreensão profunda do contexto social e cultural através de papéis e personagens e 
sua configuração, um ato que acontece paralelamente à própria construção da sociedade interacionista.

Dentro desta perspectiva, Goffman abre também para a geografia um espaço teórico para o aperfeiçoamento de métodos de pesquisas qualitativas, quando parte do pressuposto que a interação social forma a construção de significados e representações em determinados espaços.

De acordo com Gil Filho:

O espaço de representação refere-se a uma instância da experiência da espacialidade originária na contextualização do sujeito. Sendo assim, trata-se de um espaço simbólico que perpassa o espaço visível e nos projeta no mundo. Desta maneira, articula-se ao espaço da prática social e de sua materialidade imediata. (GIL FILHO, 2003, p.3)

O pesquisador pode, assim, considerar ambientes como espaços sociais, onde o comportamento humano relaciona e configura grupos sociais. Neste ambiente, a copresença física do indivíduo é uma condição fundamental para a interação, concretiza-se aqui o cotidiano.

Portanto, o interacionismo simbólico se preocupa basicamente com um conhecimento prático analisando situações sociais, que se formam através de um acervo simbólico em palcos de atuação. Para isso é necessário identificar uma ordem estrutural das interações face-a-face. Neles, o indivíduo deve (ou não) aceitar regras, como se comunicar, fazer sua manifestação visual, ou movimentar o seu corpo. Desta maneira, segundo Goffman (1996, p.77), "o corpo possui uma simbologia comunicativa expressiva de um acontecimento e conhecimento social (postura, movimentos, atitudes...)".

Desse modo é interessante observar que, como nos modelos do construtivismo social (Vygotsky, Piaget), a corporeidade e individualidade não permitem generalizações de comportamentos, mas apresentam-se como casos de estudo de processos de adaptação aos papéis sociais em permanente modificação. Assim, a preocupação das pessoas com modelos culturais e sua integração coletiva é sempre apenas uma escolha.

Neste momento vale a pena mencionar que outro sociólogo norte-americano, Talcott Parsons (1955), já denominava este tipo de processo de 'homologia' entre a 
pessoa e seu sistema social. Para Parsons, os atores internalizam valores instituídos e se controlam reciprocamente, e esse controle pode ser realizado por meio de rituais. Como Vygotsky e Piaget, Parsons também destaca a educação como um veículo cultural fundamental, onde são repassados valores.

Esta "liberdade" da ação social fez que os interacionistas da época utilizassem bastante o método científico das probabilidades. Como acharam que a comunicação nem sempre teria êxito da mesma forma, mas que uma escolha adequada dos símbolos serviria apenas o objetivo de uma interação para dar credibilidade e compreensão identificaram uma grande variedade de estratégias e representações/apresentações. Uma das estratégias principais, neste momento, é a mudança entre os diferentes palcos do cotidiano. Nestes palcos, se apresentam as encenações, onde certa convenção é "negociada" entre os indivíduos, muitas vezes para manter a estabilidade da situação, mas às vezes também para questioná-la.

Atrás dos objetivos, a metodologia goffmaniana interacionista também leva em consideração os desejos pessoais. Estes são outra forma de representação do indivíduo. Neste caso, a representação não é apenas a aparência, mas traz consigo também a intenção, a vontade muitas vezes surgindo da personalidade profunda (do in- ou superconsciente). Esta duplicação psicológica em dois níveis de aparência e de intenção pessoal explica como cada indivíduo "compreende" e organiza a sua imagem. Por isso, a metodologia de Goffman permite uma perspectiva de representação teatral entre pessoa e personagem (GOFFMAN, 1996, p.9). E o desejo ou anseio que cria no papel uma direção, a qual não acontece apenas na interação horizontal de pessoas, mas numa linha vertical onde se exprime a individualidade desejada.

Dessa maneira, cada pessoa desempenha um papel interagindo com os outros através de comportamentos físicos e verbais, mas cria também um papel de desejo que utiliza a aparência para convencer o outro de sua própria atuação por intenção. Por isso, quando o indivíduo está em contato com o outro está se auto-representando e se beneficiando de uma prática dramática, e assim, os resultados subjetivos da interação tornam-se uma socialização cultural. Isso acontece através da linguagem simbólica que ultrapassa os papéis de cada um dos indivíduos e reúne as pessoas individualizadas numa forma coletiva.

Este "ajustamento" comunicativo entre o individual e o coletivo ocorre de forma 
corporal. O corpo demonstra, por meio de sua simbologia comunicativa e sua linguagem (com posturas, atitudes - como cruzar os braços, sorrir, abaixar a cabeça - a expressão dos sentimentos dos indivíduos) cria atmosferas de interação. Assim, a ação face-a-face, corpo a corpo, se define como influência recíproca das partes. Boudon (1974) chamaria esta situação de sistemas de interdependência, ou estruturas dos reencontros sociais, e o palco dessa interação se faz através do agrupamento de corpos, onde se reconhece as vontades, desejos e expectativas individuais que são em grande medida pelo menos, determinadas por fatores sociais.

Esse palco das interações permite que, de acordo com Berger e Luckmann (1999, p.38), “a realidade da vida cotidiana apareça já objetivada, isto é constituída por uma ordem de objetos que foram designados como objetos antes da "minha entrada em cena"." Podemos falar, nesta situação, do "cenário". Vivendo em um lugar geograficamente determinado, onde se faz uso dos objetos do cotidiano, como numa sala de jantar, num restaurante, etc. (= palco), os requisitos formam situações normativas (e assim simbólicas) que são integrados nas vivências. $\mathrm{O}$ cenário faz parte das teias de relações já estabelecidas. Tal realidade se apresenta como um mundo intersubjetivo, um mundo do qual participamos conjuntamente com outros homens, como comenta Berger e Luckmann (1999, p.40).

\section{A espacialidade religiosa: A Igreja Santa Madalena Sofia Barat e Santo Expedito e relato do seu padre}

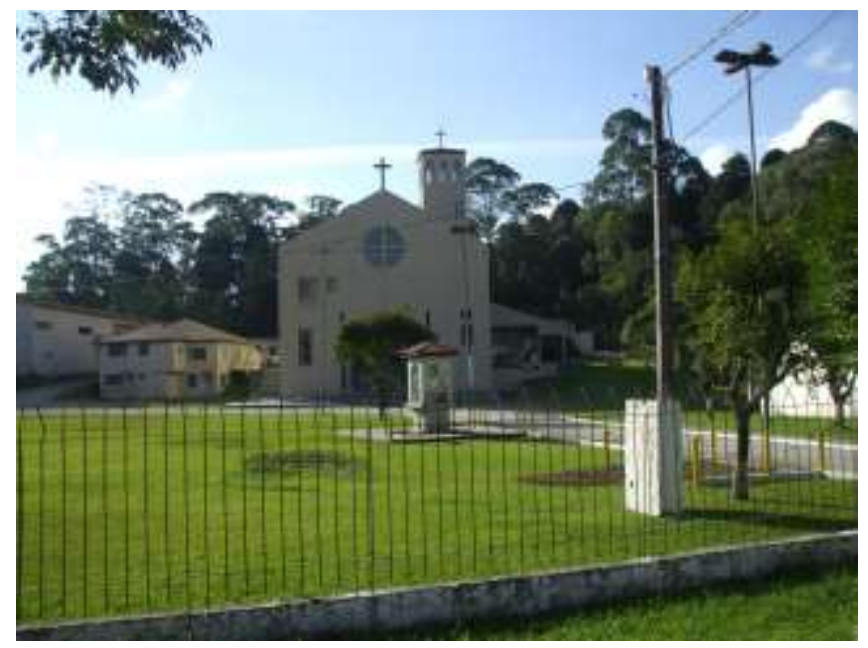


A pesquisa religiosa foi realizada na Igreja católica Santa Madalena Sofia Barat e Santo Expedito, junto com o padre franciscano do Bom Jesus, C.F.L. Essa igreja se encontra no Noroeste do bairro, perto da Avenida de Integração. Ela é uma Igreja modernista, localizado ao lado da Antiga Escola Madalena Sofia, atual ITECNE, hoje uma escola independente. Trata-se de um espaço complexo de dez mil metros quadrados, com a própria igreja, a casa do caseiro, um salão de mil e quinhentos metros quadrados, e outro salão que comporta duzentas e cinquenta sentadas, além de uma casa onde funciona a administração.

Como em cada igreja católica, já a edificação é um palco de rituais com uma história milenar. Apesar de não ser tema a configuração deste palco, os espaços criados na igreja conformam a relação entre os padres (como oficiais da igreja) e os fiéis. Mas, enquanto cada igreja, através do rito da missa, estrutura os seus papéis gerais com a comunidade, juntando todos numa única Igreja Mundial, cada igreja ganha ainda um ar específico através dos Santos. Estes representam uma apresentação de uma história individual, seja essa uma história biográfica ou uma aparição, que cria uma interligação mitológica e dialógica entre os fiéis e uma paróquia local.

Para o padre executar sua missa ele precisa seguir certo ritual social, então precisa estudar entender e estar preparado. Realiza assim seus ensaios, o que pode ser realizado mentalmente, ou na realizando "ensaios" na prática. Goffman (2012, p.91) denomina isso de planejamento, é quando uma ação complexa é planejada cuidadosamente de antemão. No caso da igreja isso é realizado, há toda uma preparação da estrutura física, da limpeza, das flores que serão utilizadas, das toalhas, da roupa que o padre utilizará, são tantos detalhes que a comunidade também ajuda a preservar.

Em nossa entrevista, o padre fez questão de ressaltar a história da igreja que comanda e suas atividades cotidianas.

O padre nos contou um pouco da história da Santa Madalena Sofia Barat. Essa foi uma santa francesa que se tornou freira no final do século XVIII. Como freira sentiu a necessidade de ajudar, durante a época de pós-guerra napoleônica, muitos necessitados, principalmente soldados que tinham voltados do front aleijados e não podiam trabalhar. Também se preocupou de crianças que ficaram sem pais tornando-se meninos e meninas de rua, pensando que uma boa educação poderia ajudar a essas crianças a sair da rua, e ficar com boa saúde física, espiritual e moral. Assim, agregou 
crianças de rua em um convento, criando os primeiros orfanatos e expandindo-os para várias partes do mundo, além de fundar instituições de educação. Com isso surgiu a necessidade de religiosas que entrassem na congregação, a qual ela denomino "Sagrado Coração", congregação essa que veio depois ao Brasil.

Em 1965, o então governador Munhoz da Rocha do Paraná instalou um povoado na região do Bairro Alto, a qual até então ainda tinha campos de pastagem (denominados Campos do Franco) que depois serviram como local de futebol. Dentro desse processo, se fez também a doação do futuro terreno da Igreja, onde se instalou também a Escola "Madalena Sofia" (que passou depois para um grupo educacional ITECNE, pois as freiras são muito idosas com mais de setenta anos).

Mostra-se no relato do padre, como a vocação da Santa está relacionada à realidade da pobreza da cidade de Curitiba, tornando o elemento apresentado pela Santa um elemento da estruturação social do bairro. Estabelece-se através dos significados sociais dos santos uma simbologia social, confirmando uma das mais antigas encenações da igreja, além da missa.

A partir de 2006, a Igreja se torna devota ao Santo Expedito. Este é um Santo extremamente popular no Brasil. Antigo soldado Romano que se tornou Cristão no exercito, e assim foi martirizado, este Santo intercede em situações de sofrimentos, e principalmente em questões urgentes.

Trata-se de um santo muito popular fazendo parte do catolicismo popular. Assim, a linguagem teatral dos santos mostra, na sua mescla, a união e interligação entre diferentes classes sociais no bairro. Essa inclusão aconteceu juntamente com a iniciativa do padre franciscano, para o qual uma preocupação dos pobres é programa ideológico.

Percebe-se que o padre é um ator fundamental na negociação do palco da igreja do bairro. Ele já tem oitenta e nove anos e está em seu oficio há vinte e dois anos (dados de 2011). Diz que sente uma vocação para essa tarefa. Mas não tem uma ligação biográfica direta com o bairro, apenas com a Igreja católica como instituição. Quanto à escolha para ser padre, C.F.L. contou que a fez mais ou menos aos com oito anos de idade. Incentivados pela família, e sendo órfão pela mãe, fez 15 anos de estudos em Rio Negro, depois em Santa Catarina e Rio de Janeiro para se formar padre. Tornou-se então prefeito de um internato de meninos, trabalho o qual estimou bastante agradável. 
Trabalhou também em Santa Catarina, Estreito, depois no Rio de Janeiro, dali foi para Clevelândia até que chegou a Curitiba, onde lecionou durante dezenove anos no colégio militar de Curitiba e dois anos no Ministério da aeronáutica. Depois ficou mais quatro anos fora, e voltou a Curitiba assumindo a direção do Hospital Santana e depois trabalhou no Hospital São Roque, Piraquara. Finalmente acabou assumindo a paróquia do Bairro Alto. Essa trajetória mostra como foi sua participação, que não realidade não ocorreu a principio como uma participação direta na comunidade, mas como papel social geral da Igreja que motivou suas atuações.

Assim, no bairro ele é um outsider ${ }^{1}$ fica bastante tempo na igreja, mas vai ao centro dormir. Suas tarefas são: realizar as missas, atender a comunidade com confissões, fazer visitas aos lares, aos pacientes nos hospitais, entre outros, criando assim uma forte interação social com a comunidade. A paróquia conta ainda com mais dois funcionários, um "faz de tudo" que também é caseiro, e um secretário que trabalha regime oito horas diárias, a igreja também recebe pessoas que realizam trabalhos voluntários, como a arrumação e limpeza da igreja.

Mostra-se, destarte, que uma igreja é tanto um lugar de socialização igualitária dentro de um bairro, na comunidade, e hierárquica, através do padre, dentro da Igreja. Assim, o padre aparece como ator em dupla função, formando a comunidade, mas também representando o mundo de fora.

A igreja é mantida pelos dízimos dos fiéis, algumas celebrações religiosas são realizadas com o dinheiro arrecadado. Também o pagamento dos funcionários e para a manutenção da igreja vem dessa fonte. A comunidade religiosa, contudo, não é apenas de moradores do bairro, vários fiéis ativos vêm de outros bairros para participarem das missas e das atividades ofertadas por essa igreja.

Nos tempos antigos, relata o pároco, as igrejas tinham um limite teórico do

\footnotetext{
1 Segundo Duncan devemos diferenciar os insiders e outsiders para entender as interações e os seus relatos. Desse modo, usaremos: (i) O discurso do outsider (inglês: aquele que vive fora) para caracterizar os eventos observados por pessoas que não vivem no bairro pesquisado, mas que podem utilizam seus serviços ou trabalham nele. Estas pessoas, muitas vezes, mantêm certo distanciamento sendo suas perspectivas diferenciadas em relação aos moradores do bairro. "O outsider pode manter um certo distanciamento crítico que o coloca numa perspectiva diferente da visão tomada como dada, ou naturalizada, das pessoas do local". (ii) O discurso do insider (inglês: aquele que faz parte de um grupo ou de um lugar) para caracterizar as pessoas que moram no bairro e que mantêm certa proximidade, até uma inserção nos próprios relatos do bairro. (DUNCAN 2004, p. 108)

Esses discursos são ativados conscientemente ou inconscientemente, e assim se revelam muitas vezes durante as entrevistas (até mesmo para os entrevistados), de que forma os atores aplicam estratégias e táticas no uso das suas aparências em interações.
} 
espaço geográfico de cada igreja, mas hoje em dia os limites devem ser rompidos, pois se a pessoa se sente bem participando de outra igreja deve participar, assim os limites acabaram se tornando ficção. Mostra-se assim a adaptação da igreja com sua instituição à flexibilidade do espaço pós-moderno. Igualmente, essa situação fortalece a função teatral das atividades, porque cada comunidade tem que ser mostrada para fora sendo atraente, assim que a paróquia consegue financiar as suas atividades. Esse sistema mais flexível lembra a antiga organização da igreja em irmandades.

O espaço fixo, o palco, é organizado para estes fins pelos próprios crentes, não só durante a missa, mas inclusive a higiene é realizada por voluntárias, como citado anteriormente, bem como as flores são doadas toda semana por um crente.

O cotidiano da paróquia é organizado de forma ritualizada e formalizada, não só dentro das missas, todos os dias às 19h, e da missa dominical, mas também pelo atendimento o dia todo aos que necessitam de uma palavra de conforto. A igreja ainda oferece cursos de catequese aos sábados. O padre além da celebração das missas procura realizar visitas aos membros da paróquia em suas casas no Bairro Alto.

Além do espaço amplo da igreja, no mesmo terreno existem dois salões que são alugados aos crentes para realização de reuniões, festas, casamentos e outros. São momentos propiciados para a interação entre as pessoas do bairro, que seguem a religião católica, sendo sempre bastante solicitados.

Outra característica interessante dessa comunidade que participa das missas é o oferecimento para trabalhar, normalmente são oferendas de serviços, "daí vem a filha, a mãe vem junto, já vem a irmã e assim vai", quando se vê tem um monte de gente ajudando, relata o pároco

Com a sua formalização ritual e a sua interação social, a Igreja representa um palco muito importante na estruturação da sociedade, principalmente quando é católica. Assim, um padre é uma pessoa que assume seu papel, vestindo-se e comportando-se de uma forma específica. Traz, consigo o ar de um ator sincero, mostrando credibilidade ao que diz, mas também criando fé (outra forma de credibilidade) dentro do sistema social.

Goffman (1996, p.25) comenta sobre a crença no papel que o indivíduo está representando. Quando um ator está inteiramente compenetrado de seu próprio número, convencido de que a sua impressão de realidade que encena é verdadeira e, passa isso aos outros, ele é um ator sincero. Por sua vez, quando não está compenetrado em seu 
papel e de sua própria prática e, não se interessa pelo que o público acredita ele está sendo cínico.

A representação eclesiástica é um elemento fundamental de sua apresentação até extinguindo, em partes, sua interioridade individual, e a credibilidade dos que estão participando. Se o padre se distanciar da comunidade, começam surgir criticas, os crentes começam a deixar de participar das atividades o que pode até enfraquecer a força coesiva da atividade religiosa.

Esse é desafio de muitos palcos sociais de quase todas as instituições religiosas no Brasil, e uma pesquisa nítida de todos os palcos religiosos no bairro seria muito interessante neste sentido.

\section{Considerações Finais}

A teoria proposta por Goffman nos faz refletir sobre a questão das representações sociais que vivenciamos no nosso dia-a-dia. Talvez as pessoas não tenham ainda percebido o quanto assumimos papéis sociais e, como esses papéis já se encontram pré-moldados para o que se escolhe fazer. No caso de uma instituição religiosa a visualização da função do padre é bem fácil de ser percebida. O padre entrevistado também estava bem ciente das funções que exerceria junto à instituição a qual escolheu para fazer parte. Dessa forma, fez sua contribuição durante anos e, continua firme em sua representação sincera e escolha de vida.

Erving Goffman é um sociólogo de grande valor para a humanidade, cremos que suas observações a respeito de atividades do cotidiano podem ser de grande valia para todos que o conheceram por meio de suas obras. Ele oferece ao público uma nova maneira de se preparar para a vida. Afinal, por meio de experiências sociais podemos nos reportar a análises e a reflexão científica da vida social.

Nosso estudo de caso foi em relação à ação do padre da igreja Madalena Sofia e Santo Expedito, o padre relatou sua trajetória de vida ao longo dos anos e sua escolha de seguir a religião. Ele procura realizar suas atividades com muita dedicação e amor, ajudando a comunidade com suas palavras e atendimentos. Em suma, portanto o padre teve uma atuação sincera, de acordo com a teoria goffmaniana, representou a contento o seu papel tanto para ele como para todos que estão envolvidos nessa paróquia. As 
igrejas representam assim um palco permanente na espacialidade, porque representam pontos de identidade e formação social, os primeiros para a sociedade em geral, mas em toda diversidade ideológica, os outros na formação de uma sociedade moderna, cuja força formadora é em grandes partes controlada pelo Estado. Ambos são instituições com uma longa história e, assim a conformação dos seus espaços simbólicos e funcionais é bastante aprofundada e ritualizada, sendo a presença de atores neles muito importante.

Percebemos que em todas as relações face-a-face há necessidade de uma reciprocidade, quer seja por meio de um olhar, de um toque nas mãos, ou mesmo pela utilização da linguagem. Ouve-se o outro, mas apenas ouvir não é o suficiente (como o caso do padre ao rezar e ler os escritos da Bíblia), é necessário, saber escutar e, procurar entender o significado de cada fala, para adotar no seu viver.

De acordo com a metodologia de Goffman os atores tentam ser sinceros ou cínicos, para posicionar-se na sociedade e, conseguir um papel para desempenhar, uma máscara que pode ser utilizada para garantir a tranquilidade social de um lado e, proteção emocional do outro. Papéis nesse sentido são criados e recriados a cada momento, em cada novo espaço, a realidade é a relação entre as pessoas. Sabemos que o teatro é uma escola da vida, porque é nele que podemos aprender atitudes para situações vividas. Assim, a base da teoria do teatro não parece científica, mas ela o é, reflete e teoriza as mesmas relações sociais que são importantes para uma geografia do cotidiano.

\section{Referências}

BOUDON, R. A Quoi Sert la Notion de "Structure"? Essai sur la Signification de Structure dans les Sciences Humaines. Paris: Gallimard, 1968.

Education, Opportunity and Social Inequality: Changing Prospects in Western Society. New York: Wiley Interscience, 1974.

DUNCAN, J. A Paisagem como Sistema de Criação de Signos. In CORREA, R. L; ROSENDAHL, Z. Paisagens, Textos e Identidade. Rio de Janeiro: RDUERJ, 2004, p. 91-132.

GIDDENS, A. \& TURNER, J., Teoria Social Hoje. São Paulo: Editora da Unesp, 1996. 
GIL FILHO, S. F. Geografia Cultural: Estrutura e Primado das Representações. Espaço e Cultura. Rio de Janeiro: NEPEC, v.19-20, p.51-59, 2005.

GOFFMAN, E. A representação do eu na vida cotidiana Petrópolis: Vozes, 1996.

Vozes, 2012.

Os quadros da experiência social. Uma perspectiva de análise. Petrópolis: Manicômios, Prisões e Conventos. São Paulo: Perspectiva, 2005.

Comportamentos em lugares públicos. Rio de Janeiro: Vozes, 2010.

Ritual de interação: Ensaios sobre o comportamento face a face. Petrópolis:

Vozes, 2011.

KAPLAN, B; DUCHON, D. Combining qualitative and quantitative methods in information systems research: a case study. MIS Quarterly, v. 12, n. 4, p. 571-586 Dec. 1988

MAFFESOLI, M. O tempo das tribos. O declínio do individualismo nas sociedades de massa. Rio de Janeiro: Ed. Forense Universitária, 2006.

Recebido: 06/02/2014

Received: 02/06/2014

Aprovado: 19/07/2014

Approved: 07/19/2014 